\title{
Perspectivas de alunos de Bacharelado em Piano quanto ao uso do software MIROR- Impro para desenvolvimento de improvisação ${ }^{1}$
}

\author{
Perspectives of undergraduate piano students on the \\ use of the MIROR-Impro software for developing their \\ improvisation skills
}

Luciana Fernandes Hamond ${ }^{2}$ Fundação de Apoio à Escola Técnica do Rio de Janeiro lucianahamond@gmail.com

Anna Rita Addessi ${ }^{3}$ Universidade de Bologna, Itália annarita.addessi@unibo.it

Submetido em 24/09/2019

10 presente trabalho foi realizado com apoio da Coordenação de Aperfeiçoamento de Pessoal de Nível Superior - Brasil (Capes) - Código de Financiamento 001

2 Professora da Fundação de Apoio à Escola Técnica do Rio de Janeiro (Faetec-RJ), Brasil. Doutora pelo Institute of Education-UCL, University College London (Reino Unido), com Bolsa Doutorado Pleno no Exterior pela Capes. Realizou pós-doutorado na Universidade do Estado de Santa Catarina (Udesc), Brasil.

3 Professora associada em Musicologia. Professora de Metodologia de Educação Musical e de Educação Sonora na Escola de Psicologia e Ciências da Educação da Universidade de Bolonha (Itália). Doutora em Musicologia. Realizou Pós-Doutorado em Psicologia da Música pela Universidade de Bolonha. 


\section{Resumo}

Estudos de pesquisa recentes forneceram evidências sobre os benefícios do uso de tecnologia digital para aprimorar os aspectos específicos na aprendizagem de instrumento e canto, no contexto de aulas individuais. A aplicação de tecnologia digital pode gerar tipos de feedback adicionais ao provido pelo professor, comumente encontrado em aulas individuais. Tipos de feedback adicionais, seja visual em tempo real, seja visual combinado com auditivo em tempo posteriori, aumentam a consciência do aluno sobre seu processo de aprendizagem. A improvisação pode ser um desafio para os bacharelandos, que têm o piano como instrumento principal em aulas individuais em que o foco está na interpretação pianística de repertório solo de diferentes períodos. O objetivo desta pesquisa é investigar o desenvolvimento da improvisação com alunos regulares do curso de Bacharelado em Piano de uma instituição de ensino superior brasileira, com o uso da interação reflexiva com o software MIROR-Impro, um dos componentes da plataforma MIROR (Musical Interaction Relying On Reflexion - Interação Musical com Base na Reflexão). Dois alunos de bacharelado tiveram duas sessões registradas em vídeo explorando o uso do software MIROR-Impro; duas entrevistas semiestruturadas foram conduzidas a fim de compreender as perspectivas dos alunos quanto ao uso desse recurso tecnológico. Os relatos dos bacharelandos auxiliam na compreensão sobre a aplicação do software MIROR-Impro, destacando seus benefícios e suas limitações, para o desenvolvimento de improvisação em instrumentos de teclado.

Palavras-chave: Educação Musical e Tecnologias Digitais. Feedback. Improvisação. Pedagogia do Piano. Sistemas Musicais Reflexivos Interativos.

\section{Abstract}

Recent research studies have provided evidence on the benefits of using digital technology to improve specific aspects of instrumental and vocal learning in the context of individual lessons. The application of digital technology can generate types of feedback additional to that provided by the teacher which are commonly found in individual classes. Additional feedback types are real-time and post-hoc visual feedback combined with auditory feedback may increase student awareness of their learning process. Improvisation can be a challenge for undergraduate students in Bachelors in Piano Performance who have the piano as the principal instrument in which the lesson focus is on developing piano technique and interpretative skills to perform solo repertoire different periods. The objective of this research is to investigate the development of improvisation with regular undergraduates of the Bachelor's Degree in Piano of a Brazilian higher education institution, using reflexive interaction with the MIROR-Impro software, one of the components of the MIROR plataform (Musical Interaction Relying On Reflexion). Two undergraduate piano major students had two sessions recorded on video for observation data whilst they explored the use of MIROR-Impro software, and were interviewed for two times; this approach was conducted to understand students' perspectives on the use of this technology system. Piano undergraduates' reports assist on the understanding of the application of the use of the MIROR-Impro software, its benefits and limitations regarding, for developing improvisations in keyboard instruments.

Keywords: Music Education and Digital Technologies. Feedback. Improvisation. Piano Pedagogy. Musical Interaction Relying on Reflexion. 


\section{INTRODUÇÃO 4}

Este artigo traz um recorte da pesquisa de pós-doutorado da primeira autora ${ }^{5} \mathrm{com}$ colaboração internacional com a segunda autora. O artigo apresenta revisão bibliográfica, metodologia, resultados parciais e discussões sobre o uso de feedback mediado por tecnologia, para o desenvolvimento de improvisação ao piano por alunos de Bacharelado em Piano, no contexto de instituição de ensino superior no Brasil. Feedba$c k$ é essencial para a aprendizagem, sendo geralmente fornecido por um agente, por exemplo, professores, colegas, livro, própria experiência em relação ao desempenho do aluno (HATTIE; TIMPERLEY, 2007). No contexto de ensino e aprendizagem de instrumento e canto presencial, o feedback pode ser intrapessoal e interpessoal. O feedback intrapessoal ocorre no interior do indivíduo: auditivo, visual e proprioceptivo, incluindo o cinestésico e o tátil (BANTON, 1995; FINNEY; PALMER, 2003; WÖLLNER; WILLIAMON, 2007). O feedback interpessoal ocorre entre dois indivíduos, podendo ser verbal ou não verbal. Os verbais envolvem os seguintes comportamentos: dar instruções, fazer perguntas, fornecer informações, prover feedback geral e outros comentários; e os não verbais englobam: tocar, tocar com o aluno, modelar, imitar como o aluno toca, fazer gestos, bater o pulso, e fazer expressões faciais (BURWELL, 2010; SIEBENALER, 1997; SPEER, 1994). O feedback interpessoal também pode ocorrer entre um indivíduo e tecnologias digitais por meio de feedback visual em tempo real em aulas de canto (WELCH et al., 2005) e em tempo real e a posteriori em aulas de piano (HAMOND, 2017), ambos no ensino superior.

Há evidências dos benefícios da aplicação de tecnologias digitais no ensino de música na escola de educação básica no Reino Unido (HIMONIDES, 2012) como ferramenta para a abordagem de ensino transformadora (SAVAGE, 2007), trazendo um ambiente de aprendizagem mais colaborativo (KING, 2008). No Brasil, o uso de tecnologias digitais em educação musical também proporciona "um espaço colaborativo para discussão, construção e formação do espírito crítico entre alunos e professores" (CERNEV, 2018, p.24), e seu uso deve ser adequado "para que as experiências de aprendizagem na música sejam significativas" (OLIVEIRA et al., 2016, p.82). No entanto, professores de música apresentam crenças de autoeficácia baixas (BANDURA, 1997) em relação às suas competências em conhecer e aplicar tecnologias digitais no contexto da educação musical (OLIVEIRA et al., 2016).

O uso de tecnologias digitais gera tipos de feedback adicionais, por exemplo o visual e o auditivo, e pode ter um impacto no ensino e aprendizagem de instrumento quando trabalhados sistematicamente junto com os tipos de feedback providos pelo professor de instrumento, o verbal e o não verbal. O feedback visual, na forma de repre-

\footnotetext{
40 texto submetido constitui uma versão ampliada de exemplar previamente publicado nos Anais da $14^{a}$ edição do Simpósio Internacional de Cognição e Artes Musicais (Simcam) promovido pela Associação Brasileira de Cognição e Artes Musicais (ABCM), realizado de 28 a 31 de maio de 2019 na Universidade Federal de Mato Grosso do Sul (UFMS), em Campo Grande (MS).

5 Esta é uma pesquisa de pós-doutorado intitulada "Improvisação em instrumentos de teclado por meio do uso de feedback gerado por tecnologia: um estudo exploratório", desenvolvida na linha de pesquisa de educação musical no Programa de Pós-Graduação em Música (PPGMUS) da Udesc, com colaboração internacional por meio do projeto MIROR-Musical Interaction Relying on Reflexion (European Commission, ICT- FP7: www. mirorproject.eu), coordenado pela Prof. ${ }^{a}$ Dr. ${ }^{a}$ Anna Rita Addessi.
} 
sentações gráficas em piano roll, quando combinado com o feedback auditivo (playba$c k$ ), tem mostrado benefícios no contexto de aula de piano de nível superior para aprimoramento de determinados aspectos da performance musical, como por exemplo articulação, dinâmica, precisão rítmica e melódica, e uso do pedal quando professor e aluno trabalham sonatas clássicas (HAMOND, 2017). Desta forma, a tecnologia digital se apresenta como uma ferramenta no ensino e aprendizagem de piano, pois torna o aluno mais consciente de seu processo de aprendizagem e de sua performance musical.

No curso de Bacharelado em Piano, objetiva-se "preparar o músico solista, onde o ensino é feito através de aulas individuais, pois demanda um grande apuro técnico para a execução de um repertório cada vez mais complexo" (DUCATTI, 2005, p.14). Em contrapartida, no curso de Licenciatura em Música, objetiva-se desenvolver habilidades funcionais no instrumento de teclado por meio de aulas de piano em grupo para preparar o licenciando para atuar como professor de música na escola básica (MACHADO, 2016) utilizando o piano ou instrumento de teclado (instrumento harmônico), para leitura e execução de linha melódica de coro infantil, para transposição e acompanhamento de coro infantil, musicalização por meio de teclado, tirar música de ouvido proposta pelos alunos, fazer arranjos para seus alunos, entre outros.

A improvisação é uma das habilidades funcionais de fundamental importância a serem desenvolvidas não só pelos alunos do curso de Licenciatura em Música (MACHADO, 2016), mas também pelos alunos de Bacharelado em Piano que ministrarão aulas de piano em grupo na formação de futuros professores de música (PIKE, 2007). Habilidades funcionais, como a improvisação e a composição, são usadas como ferramentas "para a conscientização dos elementos e conteúdos com os quais se trabalha" (DUCATTI, 2005, p.19). Devido ao foco no desenvolvimento técnico e interpretativo nos cursos de Bacharelado em Piano, a improvisação tem sido uma atividade desafiadora para alunos de graduação. Desta forma, a ausência da prática da improvisação pelo aluno de bacharelado pode refletir na sua atuação profissional como professor de piano.

Muitas vezes, o egresso do Bacharelado em Piano que não teve contato e aprendizado de piano em grupo nem com desenvolvimento de habilidades funcionais durante sua formação se tornará professor de piano dos alunos do curso de Licenciatura em Música em aulas de piano em grupo (PIKE, 2017). Essa evidência foi constatada em pesquisas com professores de piano no Brasil (COSTA, 2003) e nos Estados Unidos (CHRISTENSEN, 2000). Costa (2003, p.48) entrevistou 25 professores de ensino de piano em grupo em universidades brasileiras e constatou uma predominância de conteúdo no estudo e desenvolvimento de repertório clássico (91\%), de técnica pianística (77\%), de memorização (72\%), de escalas e arpejos (68\%) e de prática da leitura à primeira vista (63\%). Em contrapartida, as atividades de transposição (45\%), improvisação (45\%), tocar de ouvido (41\%) e composição (32\%) apresentaram menor prioridade no conteúdo programático do ensino de piano coletivo (COSTA, 2003, p.48). No contexto dos EUA, o foco do conteúdo do piano em grupo não é diferente: as principais habilidades parecem estar relacionadas ao acompanhamento, à leitura de partitura, à harmonização e à técnica (CHRISTENSEN, 2000). 
Professores de piano no contexto do piano em grupo tendem a focar no desenvolvimento de técnica pianística e de interpretação de repertório, deixando em segundo plano o ensino de habilidades funcionais. Rocha (2016) também observou uma lacuna nas ementas de disciplinas referentes ao piano em grupo em relação às práticas criativas na formação de futuros educadores musicais em uma universidade brasileira. Nota-se um ciclo vicioso: professores de piano que não tiveram experiência com habilidades funcionais - inclusive harmonização, transposição, improvisação, arranjo e composição - durante a sua formação no curso de Bacharelado em Piano têm ensinado alunos de Licenciatura em Música que precisam desenvolver essas habilidades para atuarem na escola básica. A consequência deste ciclo é o foco nas habilidades que foram o foco da formação do egresso de Bacharelado em Piano: leitura de partitura, técnica e interpretação pianística de repertório clássico. Esse ciclo se repete pela falta da prática da improvisação durante a formação do Bacharel em Piano. Desta forma, a vivência de atividades dentro da prática criativa, como improvisação, composição e arranjo, é fundamental e pode favorecer uma melhor atuação como profissional, seja como instrumentista, professor ou professor-músico (GLASER; FONTERRADA, 2007).

A improvisação e a composição musical de crianças têm sido investigadas por diversos autores (ADDESSI et al. 2017; BEINEKE, 2011; FRANÇA; SWANWICK, 2002). A improvisação é uma forma de criação musical, assim como o arranjo onde "o aluno age diretamente sobre o objeto, manipulando ideias musicais" (SWANWICK, 1979 apud DUCATTI, 2005, p.17). Além disso, a improvisação como composição pode desenvolver a criatividade, fixar conceitos e promover a tomada de decisões musicais visando ao desenvolvimento da autonomia (BEINEKE, 2003). A apresentação das composições de crianças em sala de aula faz com que elas exerçam as três modalidades do fazer musical (FRANÇA; SWANWICK, 2002) ao participarem "como compositor, executante ou audiência crítica" (BEINEKE, 2011, p.100). A atividade de composição em grupo pode proporcionar a "participação colaborativa entre as crianças e favorece a aprendizagem criativa, na medida em que envolve negociação e tomada de decisões musicais pelas crianças, que participam ativamente do processo de aprendizagem" (BEINEKE, 2011, p.101).

As atividades de composição ou improvisação de crianças por meio do uso de tecnologia digital têm sido investigadas no projeto europeu MIROR-Musical Interaction Relying On Reflexion (Interação Musical com Base na Reflexão) ${ }^{6}$. A plataforma MIROR é composta de três diferentes componentes: MIROR-Improvisation (MIROR-Impro), MIROR-Composition e MIROR-Body Gesture, que visam explorar "o paradigma da interação reflexiva que se baseia na ideia dos usuários manipularem cópias virtuais deles próprios, através de um software especificamente desenvolvido e chamado de sistemas musicais reflexivos interativos" (ADDESSI et al., 2015, p.130). Addessi afirma que

O potencial pedagógico da interação reflexiva baseia-se no fato de que o sistema estimula o sujeito a realizar um diálogo durante o qual as repetições e va-

6 MIROR-Musical Interaction Relying On Reflexion: The project was co-funded by the European Commission, under the Information and Communication Technologies (ICT), theme of the Seventh Framework Programme (FP7/2007-2013). Grant agreement n² 258338, $2010-2013$. 
riações potencializam o conflito [problema] cognitivo que a criança resolve no decorrer da interação, dando origem a um aprendizado por identificar e resolver o problema. (ADDESSI, 2014, p.223).

Os resultados de uma pesquisa a partir da observação da interação das crianças com os sistemas musicais reflexivos interativos (IRMSs Interactive Reflective Musical Systems) sugerem que "a interação reflexiva aumenta a aprendizagem musical e criatividade musical em crianças" e estão relacionados com "[a] experiência de fluxo e os comportamentos de escuta das crianças interagindo com um sistema reflexivo interativo" (ADDESSI, 2014, p.227), tendo efeito na exploração das crianças no uso de vários elementos, como, por exemplo, melodia, ritmo, registros, andamento, dinâmica e fraseado (ADDESSI et al., 2017, p.5). O estado de fluxo é "considerado a base dos processos criativos", sendo definido por Csikszentmihalyi como "experiência ótima", onde o nível de habilidade exigido para executar uma dada tarefa está em equilíbrio com o nível de habilidade que um indivíduo apresenta para executá-la (ADESSI; BONFIGLIOLI, 2017, p.185). Segundo as autoras,

O estado do fluxo é caracterizado pela presença de níveis elevados de uma série de variáveis, que são: atenção concentrada, feedback claro e imediato, objetivos claros, prazer, controle de situação, nenhuma preocupação com falhas, desaparecimento de autoconsciência, modificação na percepção do tempo. (ADESSI; BONFIGLIOLI, 2017, p.185).

O software MIROR-Impro é um programa em desenvolvimento, sendo utilizado com o propósito de pesquisas científicas, e, portanto ainda não está disponível no mercado. O uso do programa envolve o uso de piano digital ou teclado com entrada e saída MIDI (Musical Instrument Digital Interface). Dentre as funcionalidades do software MIROR-Impro está a possibilidade de gravar as improvisações ao piano digital com interface MIDI e reproduzir respostas em quatro modalidades com níveis de variação graduais: eco (reprodução exata), similar, diferente e muito diferente. Há também a possibilidade de realizar as modalidades transpostas.

Estudos prévios com crianças não treinadas musicalmente e sistemas musicais reflexivos interativos sugeriram que "uma interação baseada exclusivamente no som gera [...] um nível de fluxo mais alto", aspecto fundamental na educação musical, pois as crianças desenvolvem uma atitude de pensar o som (ADDESSI et al., 2015, p.141). Apesar de o software MIROR-Impro ter mostrado benefícios no desenvolvimento de improvisação com crianças, o software que deu origem ao MIROR-Impro, denominado Continuator, foi criado para atender adultos músicos no desenvolvimento de improvisações (PACHET, 2006), mas tem sido menos investigado para esse público. Por outro lado, um estudo-piloto com crianças e o Continuator mostrou imediatamente o potencial que a tecnologia digital pode ter na área educacional ao promover a interação reflexiva (ADDESSI; PACHET, 2005). Além disso, a prática da improvisação com sistemas musicais reflexivos interativos oferece outros benefícios, por exemplo, diminui a ansiedade (PACHET, 2006) e aumenta o estado de fluxo (ADDESSI et al., 2015; ADDESSI et al., 2017). Neste artigo, discutiremos como o desenvolvimento da improvisação por meio do sof- 
tware MIROR-Impro para o aluno de Bacharelado em Piano pode ter um efeito não só no desenvolvimento da improvisação como parte de suas habilidades funcionais, mas também pode melhorar o bem-estar do aluno em apresentações em público. Os resultados parciais dessa pesquisa são apresentados neste artigo sobre os relatos de dois alunos da última fase do curso de Bacharelado em Piano em uma instituição de ensino superior brasileira após explorarem o software MIROR-Impro para desenvolverem suas improvisações ao piano.

\section{OBJETIVO}

As investigações recentes mostram evidências do impacto que as aplicações de diversos tipos de tecnologia digitais têm na educação musical (HAMOND, 2017; HIMONIDES, 2012; WELCH et al., 2005), especificamente no ensino e aprendizagem e desenvolvimento de improvisação em instrumentos de teclado (ADDESSI, 2014; ADDESSI et al., 2015; ADDESSI et al., 2017; PACHET, 2006). Apesar de reconhecer o impacto desses resultados de estudos sobre a prática no contexto de educação musical do Brasil, onde algumas pesquisas experimentais estão em andamento (por exemplo, PSCHEIDT et al., 2019), é necessário realizar mais estudos. A divulgação e a aplicação de resultados de investigações sobre a prática de uma instituição de ensino superior podem impulsionar a adoção de práticas pedagógicas na área de educação musical que são essenciais para continuar o diálogo entre pesquisa e prática pedagógica.

O objetivo geral dessa pesquisa é investigar os usos pedagógicos do software MIROR-Impro, por meio de feedback adicional gerado por tecnologia digital no desenvolvimento de improvisação em instrumentos de teclado (piano digital), no contexto de uma instituição de ensino superior brasileira, com alunos e seus professores, para compreender as suas perspectivas sobre o uso software MIROR-Impro no curso de Bacharelado em Piano. Os objetivos específicos dessa pesquisa são: a) investigar perspectivas quanto ao uso pedagógico do software MIROR-Impro como ferramenta na improvisação em instrumentos de teclado com alunos adultos; e b) investigar os tipos de feedback visual e auditivo adicionais (playback das improvisações em sincronia com suas respectivas visualizações em piano roll) disponíveis que possam otimizar o processo da improvisação ao piano.

Tendo em vista a lacuna nas pesquisas brasileiras investigando sistematicamente o uso de tecnologias digitais na educação musical, especificamente com alunos de instrumento (piano), essa pesquisa se torna relevante. Essa pesquisa visa contribuir para um melhor entendimento do uso da interação reflexiva com software MIROR, para o desenvolvimento e aprimoramento de improvisação musical por alunos de Bacharelado em Piano, ao lado dos pesquisadores como facilitadores da tecnologia.

\section{METODOLOGIA E MÉTODOS}

A metodologia adotada nessa pesquisa foi um estudo exploratório de caso-ação 
(BRAA; VIDGEN, 1995) de natureza qualitativa. A coleta de dados envolveu registro em vídeo e observação de duas sessões com o uso do software MIROR-Impro com os dois alunos de Bacharelado em Piano; duas entrevistas semiestruturadas com os alunos; e um grupo focal com alunos e respectivo professor de piano com utilização de excertos de vídeos de sessões, registradas para discussão e debate das perspectivas dos participantes sobre o uso do software MIROR-Impro. Uma análise de dados qualitativa de métodos múltiplos foi realizada.

\section{Participantes}

Dois alunos de Bacharelado em Piano da última fase e seu respectivo professor de uma instituição de ensino superior brasileira participaram nesta pesquisa, juntamente com a primeira autora, manipulando o sistema tecnológico. Os participantes voluntários foram informados sobre os objetivos desse estudo e consentiram a participação na pesquisa, permitindo a coleta de dados em vídeo e áudio e divulgação de resultados da pesquisa, seguindo os procedimentos éticos. Os participantes desta pesquisa foram anonimizados para preservar suas identidades, garantindo a confidencialidade da pesquisa. Os dois alunos participantes da pesquisa receberam nomes fictícios: Luciano e Carlos.

\section{Materiais/ Equipamentos}

A fim de explorar o uso da interação reflexiva com o software MIROR-Impro com os alunos participantes, a pesquisa utilizou os seguintes recursos tecnológicos nas sessões: piano digital, cabos MIDI, um computador laptop rodando o software MIROR-Impro versão 3.15, uma tela de computador adicional e um cabo VGA. Os equipamentos para coleta de dados foram duas câmeras digitais (uma focando na interação do aluno e a tela de computador, e a outra focando na tela de computador), dois tripés para as câmeras digitais para as sessões e um gravador de voz, tanto para as sessões quanto para as entrevistas e para o grupo focal.

\section{Procedimentos de coleta de dados}

A coleta de dados envolveu (a) registro em vídeo de duas sessões por aluno com o uso da interação reflexiva com o software MIROR-Impro $(n=4)$ : alunos participantes foram convidados a improvisar livremente e utilizar o software mediado pelos pesquisadores (autores); (b) registro em áudio de duas entrevistas por aluno $(n=4)$; e (c) registro em vídeo e áudio do grupo focal com alunos participantes e respectivo professor $(n=1)$. O registro de vídeo das sessões foi realizado por duas câmeras, uma capturando a interação entre o participante e a tela de computador e outra capturando a tela do computador adicional. O software MIROR-Impro pode gravar e reproduzir dados correspondentes à improvisação do participante, quer imitando a improvisação do participante, quer reproduzindo uma resposta em três categorias (eco, similar, diferente ou muito diferente) num jogo contínuo entre a improvisação realizada e a audição de 
respostas geradas por computador. A visualização da improvisação foi mostrada para o aluno participante em piano roll em tempo real e em tempo posteriori na tela adicional de computador, quando o software MIROR-Impro respondia à improvisação gravada nas modalidades (eco, similar, diferente ou muito diferente). O software MIROR-Impro oferece tipos de feedback adicionais: o visual na forma de piano roll em tempo real e o visual combinado com o auditivo em tempo posteriori. O feedback visual em tempo real é gerado quando o aluno improvisa ao piano ao mesmo tempo que o software MIROR-Impro grava os dados referentes à improvisação. O feedback visual combinado com o auditivo se refere à resposta do computador, na forma de playback junto com a visualização em piano roll. A resposta do computador pode variar, dependendo da modalidade selecionada (eco, similar, diferente ou muito diferente) na interface do software MIROR-Impro.

A primeira etapa da coleta de dados consistiu no registro em vídeo de duas sessões com cada aluno participante para explorar o uso do software MIROR-Impro. Os alunos foram encorajados a improvisar livremente sem seguir nenhum estilo musical específico enquanto exploravam as modalidades do software MIROR-Impro (eco, similar, diferente e muito diferente). A Fig. 1 mostra a interface do software MIROR-Impro disponível para os alunos participantes nas sessões. O papel dos pesquisadores (autores) foi o de operar a tecnologia na sessão e apresentar as modalidades que poderiam ser exploradas. As sessões foram realizadas com intervalo de uma semana para que os alunos pudessem interiorizar e refletir sobre suas experiências em cada sessão. As sessões tiveram diferentes durações, como é mostrado na Tab. 1.

\begin{tabular}{lll} 
Alunos participantes & Sessão 1 & Sessão 2 \\
\hline Luciano & $42 \mathrm{~min}$ & 1h $13 \mathrm{~min}$ \\
\hline Carlos & $34 \mathrm{~min}$ & $41 \mathrm{~min}$ \\
\hline
\end{tabular}

Tab. 1: Duração de cada sessão com software MIROR-Impro por aluno participante.

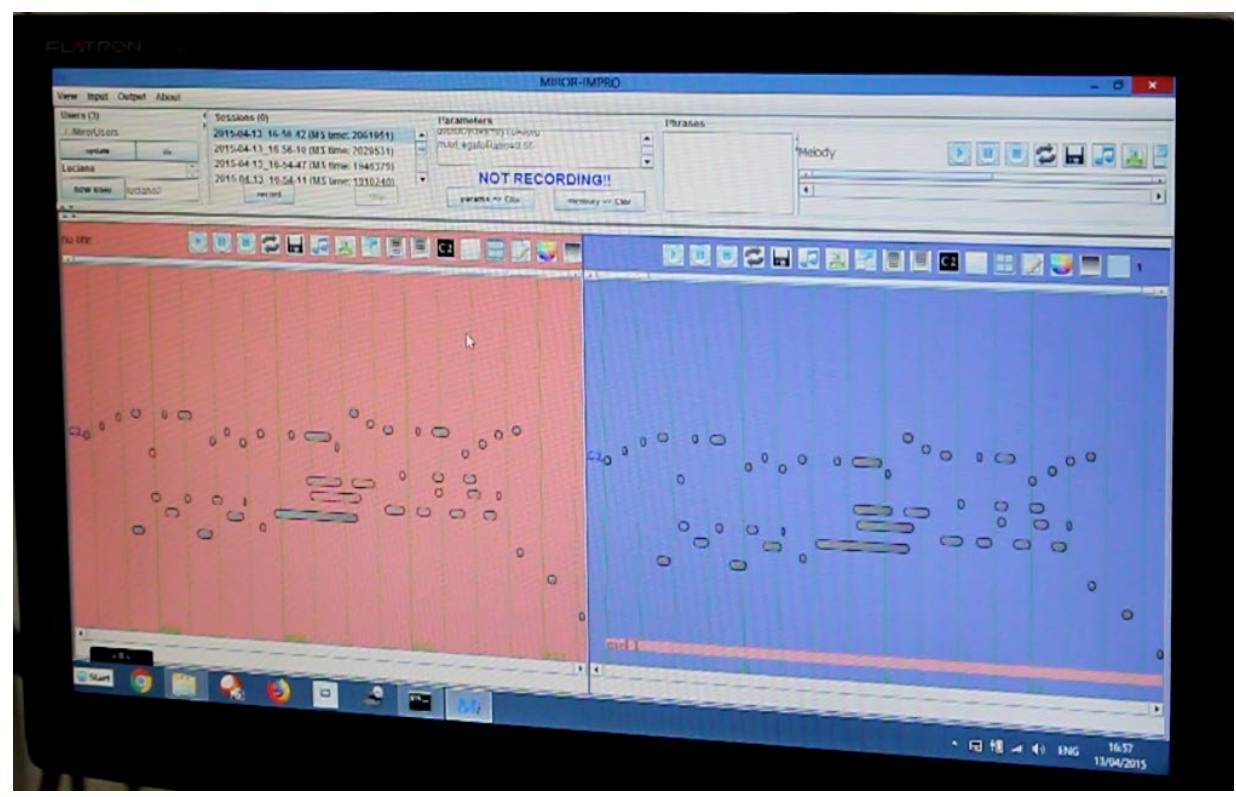

Fig. 1: Exemplo da interface do software MIROR-Impro usada na segunda sessão de Luciano: (a) à esquerda, a visualização em piano roll do que foi improvisado pelo aluno; (b) à direita, a visualização em piano roll da resposta do software MIROR-Impro. 
A segunda etapa da coleta de dados consistiu nas duas entrevistas semiestruturadas conduzidas com cada aluno participante, foco deste artigo. A primeira teve como objetivo conhecer as experiências anteriores do aluno com a prática de improvisação ao piano e de aprendizagem do piano. A segunda entrevista teve como objetivo compreender as perspectivas dos alunos em relação ao desenvolvimento de suas improvisações com o uso do software MIROR-Impro. Os alunos foram entrevistados em diferentes momentos por questões de logística de sala e disponibilidade dos alunos. Luciano foi entrevistado antes da primeira sessão e após a segunda sessão, enquanto Carlos foi entrevistado após cada sessão, com o uso do software MIROR-Impro. Esse fato pode ter influenciado a memória acerca das perspectivas em relação às experiências para a primeira e segunda sessões, respectivamente. As entrevistas semiestruturadas tiveram diferentes durações, como é ilustrado na Tab. 2.

\begin{tabular}{lll} 
Alunos participantes & $\begin{array}{l}\text { Entrevista após } \\
\text { sessão 1 }\end{array}$ & $\begin{array}{l}\text { Entrevista após } \\
\text { sessão 2 }\end{array}$ \\
\hline Luciano & $20 \mathrm{~min}$ & $36 \mathrm{~min}$ \\
\hline Carlos & $39 \mathrm{~min}$ & $40 \mathrm{~min}$ \\
\hline
\end{tabular}

Tab. 2: Duração de cada entrevista semiestruturada por aluno participante.

A terceira etapa da coleta de dados envolveu um grupo focal com os alunos participantes e seu respectivo professor, com duração de 1 hora e 10 minutos. No grupo focal, o professor e seus alunos observaram três trechos de vídeos das sessões usando o software MIROR-Impro, seguidos de reflexões e discussões sobre as suas perspectivas quanto ao uso do software MIROR-Impro no desenvolvimento de suas improvisações.

\section{Análise de dados}

Este trabalho apresenta resultados obtidos a partir da análise temática (BRAUN; CLARKE, 2008) das entrevistas semiestruturadas ${ }^{7}$ realizadas com os dois alunos de piano participantes. As próximas etapas de análise qualitativa de dados serão a triangulação dos dados coletados - registros em vídeo das observações, das entrevistas e do grupo focal - para assegurar confiabilidade ou trustworthiness (GUBA, 1981) desta pesquisa.

\section{RESULTADOS}

\section{Experiências com o piano e com a prática da improvisação}

Os alunos apresentaram diferentes experiências com o piano e com a prática da improvisação. Luciano (23 anos) possui experiência com o piano (desde seus 6-7 anos), com violão e guitarra, e sempre buscou conhecimento sobre música popular, arranjo e improvisação fora da universidade, ao mesmo tempo que demonstra interesse no 
repertório clássico. Carlos (21 anos) possui experiência com o instrumento de teclado desde seus 14 anos, toca instrumentos de sopro, como o saxofone, e relatou ter tido pouco contato a com improvisação livre, conhecimento que adquiriu em grupo de música experimental em um projeto de um dos professores da universidade. As diferentes experiências que os alunos de piano apresentam terão um efeito tanto no desenvolvimento de suas improvisações quanto nas suas crenças de autoeficácia em relação às suas práticas de improvisação.

Quanto ao uso de tecnologia na sua prática musical, Luciano tem experiência em usar sequenciador MIDI para fazer arranjos com baixo e bateria e usar o play along para improvisar ao piano sobre a gravação MIDI, além de ter relatado prática com gravação de áudio; Carlos tem o costume de gravar suas performances utilizando mais comumente o registro em vídeo.

A necessidade de realizar no mínimo duas sessões para explorar o software MIROR-Impro é uma evidência para a avaliação da tecnologia, tendo em vista que na primeira sessão os alunos participantes ainda estão se adaptando à nova experiência, e, na segunda sessão, os alunos parecem estar mais familiarizados e mais confiantes ao lidar com a tecnologia e com as modalidades de resposta do software:

A experiência em si já era diferente de tudo que eu já [estava] acostumado, foi um pouco estranho... (Luciano, entrevista 2).

Na semana passada, [...] [eu] não sabia do que se tratava, assim... como ia ser a experimentação e interação com o software (Carlos, entrevista 2).

Nessa sessão [segunda sessão] eu [estava] bem mais confortável em relação a tudo, tanto o programa, quanto improvisar e ver o feedback, [estava] bem mais relax, assim [...] acho que também [estava] bem mais acostumado com o tipo de feedback que o programa dá (Luciano, entrevista 2).

Desta forma, na segunda sessão, os alunos participantes relataram maior compreensão quando exploraram o software MIROR-Impro para desenvolverem suas improvisações.

\section{A percepção do aluno em relação ao que foi improvisado com o MIROR-Impro}

O feedback visual, na forma de visualizações em piano roll, estava disponível aos alunos durante a realização da improvisação e enquanto as respostas do software MIROR-Impro eram reproduzidas durante as duas sessões e pareceu dar suporte ao processo de desenvolvimento da improvisação nas sessões. O feedback visual adicional nas sessões, tanto no tempo real quanto a posteriori (playback), combinado com o feedba$c k$ auditivo, parece ter mudado a percepção do aluno em relação ao que foi improvisado e pareceu deixar os participantes mais conscientes sobre suas improvisações e as respostas oferecidas pelo MIROR-Impro:

Já me gravei para estudar, mas daí era áudio e eu só me ouvia [...] E [eu] nunca me gravei para ver o que que o programa faz com o que eu toco e tal, então foi uma experiência bem diferente com o que eu já tive [...] E ver isso graficamente 
também... Isso na hora que [estou] tocando... e aí, depois, ver isso graficamente mudou minha percepção sobre o que eu [estava] tocando, porque sei lá, [você] vê os motivos, [você] vê visualmente o tipo de textura que [você] usou aqui, [você] usou ali e [você] usou ali... (Luciano, entrevista 2, grifo nosso).

Ter o visual também faz diferença, assim... é...[...] Acho interessante ver tanto o aspecto rítmico como a organização de alturas, ver o som visualmente, no piano roll, tem a ver com as alturas, e a gente vê ao longo do tempo como algo corrente, é interessante ver o trecho sonoro materializado de alguma forma (Carlos, entrevista 2, grifo nosso).

No contexto de exploração do software MIROR-Impro com alunos adultos com experiência prévia com improvisação (em diferentes níveis), a visualização em piano roll parece ter impactado positivamente, mudando a percepção dos alunos do que eles tocaram e aumentando a consciência de aspectos melódicos, rítmicos e de texturas utilizados na improvisação. Por outro lado, no contexto da educação infantil, a presença de uma tela de computador mostrando visualizações parece ter distraído as crianças não treinadas musicalmente, usando o software MIROR-Impro, causando uma diminuição do foco na atividade de improvisação em alguns momentos em pesquisa anterior (ADDESSI et al., 2015).

\section{A consciência de seus processos de improvisação}

A associação do feedback visual, na forma de notação piano roll ou MIDI, com a notação musical é uma evidência de que os alunos participantes aumentaram a consciência de seus processos de improvisação em relação aos parâmetros musicais escolhidos, por exemplo, na escolha de padrões rítmicos, melódicos, uso de texturas (melodia acompanhada, arpejos, contraponto) e harmonia, como ilustram os relatos:

Eu penso que esse jeito de se gravar em MIDI, improvisar e ver, pode ser um bom jeito de estudar texturas diferentes na improvisação, né, tipo... "Ah, vou fazer um ponto, um negócio mais contrapontístico, agora vou fazer um negócio com nota pedal." Que [você] vê a nota pedal, vai aparecer um riscão [risco grande], e a melodia em cima. (Luciano, entrevista 2, grifo nosso).

Achei interessante essa possibilidade de interação e reação, essa coisa de resposta, o próprio feedback visual que a gente tem quando ele gera o piano roll... e também perceber o modo como ele interage mesmo, [...] perceber coisa de ritmo e definição é... de estrutura da música, aspecto rítmico e uma coisa que eu percebi hoje foi a direção das coisas assim, a direção das frases e figuras e disposição assim... como o todo da música, acho que esses aspectos mesmo, melódicos, rítmicos, alguma coisa de harmonia também, intervalos... (Carlos, entrevista 2, grifo nosso).

Dentre as modalidades de resposta utilizadas pelo software (eco, similar, diferente e muito diferente), a utilização da modalidade eco, onde a reprodução foi idêntica à improvisação sem alteração alguma, pareceu ser bem útil para ambos os participantes pelo fato de eles perceberem auditiva e visualmente os elementos que utilizaram em suas improvisações e se tornarem mais conscientes sobre o processo de improvisação 
e de suas próprias improvisações.

Com o eco eu fiquei muito nessa posição disso, de tocar e me ouvir e de me avaliar [...]. Eu aplicaria mais acho que é o negócio do eco, que eu usaria mais [...]. Ah, essa finalidade de eu gravar e me ouvir ou estudar o meu som, meu improviso assim... os meus recursos (Luciano, entrevista 2).

No eco ele repete idêntico, daí é interessante perceber e escutar logo após tocar, é outra percepção, né, de tu [estares] improvisando e escutar logo após o que tu tocou (sic), então tem essa relação da escuta mesmo, do que tu produziu (sic). (Carlos, entrevista 2).

Por meio da modalidade eco, os alunos participantes tiveram a oportunidade de ouvir e ver versões espelhadas de suas improvisações, de refletir sobre suas improvisações, de se autoavaliar e de se tornar mais conscientes dos elementos musicais, sejam eles melódicos, rítmicos, harmônicos, de textura ou de estrutura musical presentes em suas improvisações. Esse resultado se alinha aos resultados de pesquisas anteriores (ADDESSI et al., 2015) com observação de aumento do estado de fluxo em crianças de 6-7 anos improvisando por meio da interação reflexiva com o uso do software MIROR-Impro na modalidade SAME=SIMILAR.

No contexto de alunos de Bacharelado em Piano, o feedback visual disponível na forma de piano roll, correspondente às suas improvisações gravadas e às respostas dadas pelo software, parece ter aumentado a consciência dos alunos sobre seus processos de improvisação. Portanto, os benefícios da presença da visualização em piano roll durante o uso do MIROR-Impro parecem depender do nível de treinamento musical e da capacidade de associação entre a visualização em piano roll com a notação musical e com o resultado sonoro desejado/alcançado. O feedback visual terá um impacto no seu processo de improvisação principalmente se esse feedback visual fizer sentido para o aluno.

\section{Os tipos de interação dos alunos e a tecnologia}

Apesar de os alunos participantes mostrarem preferências quanto ao uso da modalidade eco, as interações com o MIROR-Impro se deram com a utilização de as outras modalidades, onde a resposta apresentava variações da improvisação original. Os tipos de interação dos alunos e a tecnologia tiveram características diferentes. Luciano se interessou em descobrir a lógica do funcionamento do software por meio de suas respostas do software. Luciano interagiu com a tecnologia de modo que parecia brincar como se estivesse num jogo ao testar diferentes padrões e tentar compreender como o software funcionava a partir das respostas que o software oferecia para cada modalidade utilizada:

E hoje [segunda sessão] acabou que eu fiquei mais curioso com o programa, sabe? Então eu quase que toquei... hoje eu toquei mais em função de "está bom, vamos ver o que que o programa faz com isso aqui e tal. [...] A minha ideia era assim: Vou tentar sacar o melhor possível o que que ele faz para pensar mais objetivamente [...] o que que eu gostaria de usar, o que que daria para usar assim 
e tal"... Aí foi um pouco esquisito, porque algumas coisas pareceram muito aleatórias, e eu não consegui entender nada, e [em] outras deu para ter uma ideia mais clara, assim... [...] Aí com a similar, a diferente e a muito diferente, virou mais uma experimentação do programa. (Luciano, entrevista 2).

Por outro lado, a interação de Carlos com a tecnologia foi a de observar quais elementos a tecnologia selecionava a partir de sua improvisação ao oferecer a resposta de volta, fazendo com que Carlos ficasse mais consciente dos elementos que ele pouco utilizou e que poderiam ter sido mais explorados na sua improvisação. Talvez a resposta do software tenha deixado claros alguns elementos usados na improvisação de Carlos que a princípio não estavam tão evidentes:

\begin{abstract}
Teve outra coisa também na sessão passada [primeira sessão]. [...] ao longo da música eu usei algo com terças assim... eu não dei muita atenção para isso, mas, na hora do programa responder, ele deu destaque a esse elemento. Isso me fez chamar atenção a isso. Quando ele usou isso na variação, isso me deu ideia de direcionar a minha improvisação para essa ideia. (Carlos, entrevista 2, grifo nosso).
\end{abstract}

A partir dessa interação da resposta que ele dá, talvez seja possível perceber outras coisas a partir do material que eu improvisei [...]. "Quando ele te dá o feedback [...], ele te dá o... sei lá... é... tipo... [uma] evidência de algumas coisas para [chamar] a minha atenção, assim... Enxergar certos elementos da improvisação. (Carlos, entrevista 1).

Gosto de ver quando ele varia mais, acho que quando a gente usou o avançado com transposição, achei legal. Gosto de ver ele variando mais o material e perceber essas coisas que ele faz. (Carlos, entrevista 2).

Ambos os alunos tiveram interação reflexiva com as modalidades que variavam a resposta (similar, diferente e muito diferente). No entanto, as interações se deram de maneira muito individual para cada aluno: (1) interação reflexiva na forma de jogo onde o aluno improvisa na tentativa de compreender as respostas do software MIROR-Impro; e (2) interação reflexiva na forma atentiva - onde o aluno improvisa e presta atenção nos elementos de sua improvisação que foram selecionados e usados na resposta pelo software MIROR-Impro.

\title{
Aspectos técnicos a serem otimizados em relação às sessões com o MIROR-Impro
}

Os alunos participantes relataram três aspectos técnicos que parecem ter efeito nas suas improvisações no contexto desse estudo especificamente, quando exploraram o uso da interação reflexiva com o MIROR-Impro. O primeiro aspecto técnico relatado pelos participantes desta pesquisa foi o intervalo de tempo entre as improvisações e as respostas oferecidas pelo programa, considerado curto. O parâmetro intervalo de tempo usado foi o que já estava programado no software MIROR-Impro antes de as sessões começarem. Esse intervalo de tempo para o computador dar a resposta poderia ser alterado antes de iniciadas as sessões. No entanto, nesta pesquisa os alunos participantes perceberam que o silêncio (pausa) entre o término da improvisação (informação de entrada) e a resposta do software MIROR-Impro pareceu ser curto. Em alguns casos, 
a resposta do computador iniciava antes do previsto, ou seja, interrompia e finalizava a improvisação do aluno, apresentando um impacto no processo de improvisação dos alunos. Nessa pesquisa, uma pausa mais longa nas improvisações era interpretada pelo programa como término da improvisação, fazendo com que o MIROR-Impro respondesse imediatamente após a pausa longa.

Durante a improvisação, você resolve incluir no discurso ali um silêncio, esse silêncio tem duração máxima de um segundo, se não, né... do tempo ali... se não, o programa vai... Vai acabar a tua improvisação... (risos) [...]. Ele vai cortar o teu solo ali e tal (risos). (Luciano, entrevista 2).

Teve aquela coisa das pausas, que às vezes ele [o computador] corta a partir da pausa e não capta mais nada. Acho que isso limita o que pode ser tocado, o ataque ali, que ele tem a resposta de acordo com o tempo, que é bem curto, daí algumas vezes teve isso de eu ignorar quando ele respondia nesses momentos de pausa. (Carlos, entrevista 1).

Este aspecto técnico não é uma limitação do software MIROR-Impro, pois este parâmetro intervalo de tempo poderia ter sido alterado por meio de um ajuste do tempo de resposta anteriormente à coleta de dados, ou seja, antes de começar a sessão com os alunos participantes. Apesar de o software MIROR-Impro ter sido explorado pelos pesquisadores, a necessidade de realizar algumas alterações prévias em relação a alguns parâmetros só se tornou evidente durante as sessões na coleta de dados. No entanto, o intervalo de tempo de resposta do software MIROR-Impro foi uma limitação inerente ao cenário experimental desse estudo especificamente, mas poderia ter sido contornada.

Por outro lado, mesmo ao se deparar com essa limitação do tempo de resposta, Carlos relatou que essa consciência em relação ao intervalo de tempo o forçou a buscar caminhos para superar esse problema, dando a ele certa estrutura e levando-o a interagir mais com a tecnologia.

\footnotetext{
Apesar de limitar o que eu [estava] pensando de material e duração, ele também conduziu e direcionou a minha improvisação para, sei lá... uma descoberta de... é... como superar talvez esse problema... acho que foi um caminho, uma direção que levou para outra experimentação... que surgiu da interação com o software. (Carlos, entrevista 1).
}

Uhum... é esse negócio também da resposta ali... tempo de ataque, daí na hora teve várias vezes que me desestabilizou, mas ao mesmo tempo que [...] me limitou, [...] me direcionou à minha improvisação. (Carlos, entrevista 1).

A segunda limitação do uso do software MIROR-Impro foi a questão do uso do pedal, que não é gravado. As improvisações eram realizadas com pedal, mas as respostas do software não soavam com a ressonância do pedal. Como a informação MIDI do pedal não era gravada, a mesma não era replicada na resposta oferecida pelo software. Essa questão de as respostas do software não soarem com o pedal causou uma interferência no processo de improvisação dos participantes, influenciando no estilo, caráter e gêneros musicais escolhidos pelos participantes.

O negócio do pedal fez muita falta [...]. Ah, tu perde (sic) recurso, você tem um piano sem pedal, e aí? Improvisa com um piano sem pedal e improvisa com um 
pedal [...]. Tem algumas coisas que eu fiquei desconfortável de fazer em andamento lento, porque... Sabe, tem umas texturas assim que você dá uma nota grave "POM" (canta uma nota grave); aquilo fica soando, e aí você bota o arpejo em cima, deixa o negócio soando e tal.......]. Ou o próprio uso de harmônico do piano, você [está] tocando sem pedal, mas em algum acorde ali você bota um pedalzinho para dar mais som e tudo [...], mas, em geral, é uma perda muito grande [...] de sonoridade, de textura, enfim... O cara perde um som do piano. (Luciano, entrevista 2).

Essa questão do pedal foi real, porque muda bastante a sonoridade mesmo. (Carlos, entrevista 2).

A terceira limitação está no uso do piano digital ao invés do piano acústico. Os alunos de Bacharelado em Piano usam comumente pianos acústicos em suas aulas e em suas apresentações públicas. No entanto, usar a tecnologia digital junto ao piano digital parece ser uma ferramenta a mais para que os alunos pianistas desenvolvam suas improvisações, reflitam sobre o que ouviram e viram, e assim realizem um automonitoramento e autoavaliação. A reprodução dos dados referentes às improvisações dos alunos por meio do feedback adicional (visual e auditivo) parece deixar os alunos mais conscientes e aumentar a capacidade de memorização de aspectos de suas improvisações.

O uso do piano digital apresenta seus benefícios aliados ao uso da tecnologia quando se trabalha com um objetivo claro e definido para o desenvolvimento de improvisações. No entanto, a situação ideal para Luciano seria usar um Disklavier da Yamaha ${ }^{8}$. O Disklavier é um piano híbrido que apresenta as mesmas características de um piano acústico - instrumento que os alunos de Bacharelado estão mais familiarizados -, mas que é construído para possibilitar gravações e reproduções através de interface MIDI, podendo ser acoplados ao uso de tecnologias digitais como a do software MIROR-Impro:

Porque em um piano acústico, mesmo que eu me grave improvisando, às vezes... É que depende da memória, do ouvido do cara também, mas se eu improviso, gravo e vou lá ver o que que eu fiz, não fica tão claro quanto se eu tenho como ouvir e como ver, e como talvez exportar uma partitura, como tem o recurso ali... [...] Então acho que a tecnologia num piano digital dá mais ferramenta para estudar um improviso do que um piano acústico dá... eu tenho essa impressão... [...] O ideal, para mim, seria ter um piano acústico com o MIDI, com a tecnologia... (Luciano, entrevista 2).

Sempre é diferente não tocar no piano [acústico], só que, na verdade [...], na prática corrente, estamos sempre usando piano de armário ou piano digital mesmo. (Carlos, entrevista 2).

Desta forma, dentre os três aspectos técnicos que se apresentaram como limitações no uso do software MIROR-Impro, para os alunos participantes desta pesquisa, estão: (a) a primeira limitação - intervalo de tempo entre a execução das improvisações e a resposta do software MIROR-Impro - poderia ter sido manipulada pelos pesquisadores (autores) ou pelo mesmo usuário; (b) a segunda limitação não tem solução por

8 Disponivel em: https://br.yamaha.com/pt/products/musical_instruments/pianos/disklavier/index.html. 
enquanto, pois o software não grava o uso do pedal como informação; e (c) a terceira depende das perspectivas dos alunos tanto em termos de suas experiências com o uso de piano digital quanto em termos da facilidade do uso do piano digital como mediador para gravar e reproduzir os dados MIDI através de tecnologias digitais. Provavelmente esses aspectos técnicos são considerados como limitações pelos alunos participantes, porque a referência que os alunos possuem é o contexto das aulas individuais de piano. O fazer musical mediado pelo uso de tecnologias digitais pode trazer adaptações e inovações tanto nas formas de tocar ou improvisar ao piano dos alunos quanto nas práticas pedagógicas pelos professores.

\section{Estado de fluxo versus crenças de autoeficácia quanto à improvisação ao piano}

Para Carlos, a experiência de improvisar com o uso da interação reflexiva com o software MIROR-Impro parece ter promovido o estado de fluxo pela interação que ele teve com a tecnologia. O aluno relata que não entra em estado de fluxo quando improvisa sozinho:

É uma coisa que não está em fluxo na experiência da improvisação, mas entra em fluxo pela interação que tu tem (sic) com a tecnologia, tanto isso como na questão anterior... [...] É, eu penso em fluxo como tipo... quando tu [estás] improvisando fica tudo meio... Caótico, assim... parece que tudo é imprevisível. (Carlos, entrevista 1).

O uso de sistemas musicais reflexivos interativos pode aumentar o estado de fluxo, base para os processos criativos, de crianças de 8 anos trabalhando em duplas ao desenvolverem improvisações com o uso da interação reflexiva com o software MIROR-Impro através do "mecanismo de espelhamento, repetição e variação, imitação, revezamento e intervalo de tempo regular de revezamento, que caracterizam a interação reflexiva, mostrando que são capazes de criar experiência de fluxo, bem-estar e criatividade"9 (ADDESSI et al., 2015, p.140). Nessa pesquisa, o aluno de piano parece ter entrado em fluxo através da interação reflexiva com as respostas do computador que apresentavam tipos de feedback de natureza diferente àquele habitual sobre aspectos melódicos, rítmicos e de textura. Apesar de o aluno não estar interagindo com outro aluno - que ocorreu na pesquisa com crianças (ADDESSI et al., 2015) -, o estado de fluxo para o aluno de graduação parece ter sido criado a partir do mecanismo de repetição e variação das improvisações realizadas pelo próprio aluno e pelo aumento da consciência de seu processo de improvisação.

Em contrapartida, mesmo depois de ter improvisado e interagido com a tecnologia, Carlos relatou ter uma crença de autoeficácia baixa em relação à sua capacidade de improvisar ao piano. Os pesquisadores precisaram confirmar ao aluno que ele tinha improvisado para que acreditasse, mesmo mostrando uma resposta emocional por meio de risos, que sua improvisação tinha sido aprovada por alguém, no caso, como mostra

9 Texto original: "mechanism of mirroring, repetition and variation, imitation, turn-taking, and regular timing of turn, which characterize reflexive interaction, showing that they are able to create flow experience, well-being and creativity processes" (ADDESSI et al., 2015, p.140). 
o diálogo, pelos pesquisadores:

Eu acho que a minha improvisação não deu muito certo [...]. Eu acho que eu improvisando não dá muito certo. (Carlos, entrevista 1).

Você improvisou! Você percebeu que você improvisou? (Pesquisador 1, entrevista 1).

É... é... é.. (risos). (Carlos, entrevista 1).

Possivelmente, alunos de Bacharelado em Piano que não possuem experiência em improvisar tenham essa crença de que não sabem improvisar, mesmo tendo evidências, por meio de registros, de que improvisaram. Talvez a ausência de um professor que ofereça feedback ou avalie sua improvisação tenha deixado o aluno com a impressão de que não improvisou ou de que sua improvisação não foi adequada. Além disso, o papel da primeira autora foi o de manipular a tecnologia para explorar o uso da interação reflexiva com o software MIROR-Impro, enquanto os alunos são convidados a improvisar livremente ao piano. Desta forma, observa-se a necessidade de a prática de improvisação ser regular para que haja não só o desenvolvimento da habilidade de improvisação, mas também o aumento da crença de autoeficácia dos alunos.

\title{
A prática de improvisação no curso de Bacharelado em Piano
}

Os participantes relataram que não conseguem imaginar o uso do software $\mathrm{MI}-$ ROR-Impro nas suas aulas de piano no curso de Bacharelado em Piano, onde o foco é no repertório escrito e a prática da improvisação não é conteúdo dessas aulas. No entanto, participantes sugeriram o uso do software MIROR-Impro com a modalidade eco para analisar suas interpretações dos repertórios estudados dentro das aulas de piano:

\begin{abstract}
Ah, talvez fosse interessante para ter mais assim... [...] tu tocas a peça inteira... é difícil tu mesmo ou o professor lembrar das dificuldades que tu tens naquela peça, naquela hora e tal... [...] E aí daria para ter aquela referência visual e até ver "[...] aqui foi a sessão que você mais... parou, travou", né, "Ah, talvez aqui foi uma falha de memória, aqui você esbarrou nota para caramba, vamos ver isso aqui". (Luciano, entrevista 2).
\end{abstract}

As aulas de piano sempre partem para algo mais técnico, de ter a partitura ali, de ter estratégias de estudo... Repetir alguns trechos. (Carlos, entrevista 2).

Talvez a prática da improvisação para alunos de Bacharelado com o software MIROR-Impro tenha mostrado que tal tecnologia digital pode ser uma ferramenta para desenvolver essa habilidade, principalmente para os alunos que não têm experiência de improvisar ou para aqueles que acreditam que não são capazes de improvisar. Há uma tendência em acreditarmos que os alunos de Licenciatura improvisam e que os de Bacharelado, não. No entanto, os relatos dos alunos participantes dessa pesquisa trazem evidências de que a familiaridade com técnicas de improvisação vai depender da experiência prévia que cada aluno traz, independentemente de serem alunos de licenciatura ou de bacharelado. 
Segundo Welch (2017, p.14), "os equívocos a respeito da natureza do comportamento musical, que levam a crer que as pessoas são 'musicais' ou 'não musicais', são parte do folclore sobre a música". Pesquisas recentes mostram evidências de que todo indivíduo é musical e de que cada um é único em termos musicais (e.g., ZATORRE; PERETZ, 2001 apud WELCH, 2017) e pode melhorar e desenvolver suas habilidades no fazer musical quando em ambientes apropriados (e.g., WELCH; RUSH; HOWARD, 1991 apud WELCH, 2017). Assim como as pesquisas recentes argumentam que "todos nós somos musicais; nós apenas precisamos de oportunidade" (WELCH, 2017, p.41), pode-se dizer que todos nós somos capazes de improvisar. A habilidade de improvisar pode ser desenvolvida quando encontramos as condições favoráveis num ambiente de ensino e aprendizagem que possibilite essa atividade.

Os relatos dos alunos participantes sobre o uso da modalidade eco do software MIROR-Impro numa aula de piano se alinham com resultados de uma pesquisa recente (HAMOND, 2017), na qual o uso de tecnologia digital que gera tipos de feedback adicionais (visual e auditivo) durante a aula de piano, ao lado do feedback dado pelo professor, aumenta a consciência de alunos de piano em relação a alguns aspectos específicos de suas performances, como articulação, dinâmicas, precisão rítmica e melódica, e de seus processos de aprendizagem.

Os resultados dessa pesquisa se baseiam em relatos dos alunos explorando o software MIROR-Impro individualmente, na ausência de seus respectivos professores, assim como ocorreu em pesquisas anteriores (ADDESSI et al., 2017), onde o uso do software MIROR-Impro foi explorado com crianças fora de uma aula de música. Futuras pesquisas podem investigar o uso do software MIROR-Impro no contexto de aulas individuais de piano na presença de professor e aluno ou com alunos sem experiência prévia com a improvisação.

\section{Perspectivas sobre o uso do MIROR-Impro na prática individual}

Os alunos participantes relataram sobre as suas visões em relação ao uso da interação reflexiva com o software MIROR-Impro nas suas práticas individuais, ou seja, nos seus estudos em casa. Para Luciano, o software MIROR-Impro pode ser utilizado para duas finalidades: (1) para o desenvolvimento de improvisações e (2) para o estudo de repertório pianístico.

Aí eu usaria no negócio da improvisação, isso que já comentei várias vezes, né, improvisar, me ouvir, ver aquilo visualmente, tentar fazer de novo e tal... manter ideias boas e tirar as ruins e acho que eu tentar, no caso de eu ter um piano com interface MIDI, o que não é o caso e não vai ser tão cedo, acho, também (risos), mas eu tentaria... (Luciano, entrevista 2, grifo nosso).

Num repertório de concerto também assim [...] de ter a referência visual do que eu [estou] tocando e aquele registro, a partir daquilo eu pensar o que que eu vou estudar mais, como eu vou estudar e tal... [...]. Acho que eu tive a preferência pelo eco assim [...]. Eu acho que eu mais usaria no tipo de estudo que eu faço, assim, que é o negócio de gravar e de me ouvir, ver o que que foi legal, ter aquela referência visual. (Luciano, entrevista 2, grifo nosso). 
Para Carlos, a aplicação da tecnologia parece ser útil, pois possibilita ter acesso a um outro tipo de informação, um tipo de feedback sobre a sua performance que pode ser útil na ausência do professor ou de um colega, por exemplo. Carlos relata que as variações nas respostas dadas pelo software MIROR-Impro permitem que ele perceba os novos elementos musicais que vão sendo apresentados. $O$ aluno participante também enfatiza que a interação com a tecnologia e as visualizações facilitam sua percepção sonora, e que a modalidade eco poderia ser usada na prática de repertório:

Gosto de ver quando ele varia mais [...], gosto de ver ele variando mais o material e perceber essas coisas que ele faz. (Carlos, entrevista 2, grifo nosso).

Acho interessante ter essa interação de reposta outra, assim como na gravação, mas ter o visual também faz diferença [...], mas acho que, para a prática de interpretação, seja algo que não precise das variações. (Carlos, entrevista 2, grifo nosso).

Os resultados das entrevistas com os alunos participantes sugerem dois principais usos do software MIROR-Impro: uso da modalidade eco e uso das outras modalidades com variações das respostas. Primeiro, o uso do feedback adicional posteriori, que pode ser utilizado por meio de gravação de improvisações em DAW software, parece aumentar a consciência dos alunos sobre as improvisações. A visualização em piano roll, referente às improvisações gravadas, fornece uma visualização de parâmetros musicais, como melodia e ritmos escolhidos, textura e tipos de acompanhamentos utilizados, que, no contexto tradicional, seriam trabalhados ao nível auditivo. A visualização foi relatada por ambos os alunos participantes como central nessa pesquisa, tanto no uso da modalidade eco para o estudo de aspectos técnico-interpretativos de repertório tradicional quanto no uso das variações para o desenvolvimento de improvisação ao piano. O desenvolvimento musical através de elementos como a melodia, o ritmo e a textura, pelo usuário, através do uso do software MIROR-Impro, foi mencionado em pesquisas anteriores (ADDESSI et al., 2017). Segundo, o uso das modalidades similar, diferente e muito diferente favorece a interação reflexiva entre os alunos e o software MIROR-Impro, promovendo o desenvolvimento de improvisações ao piano. A resposta do computador torna-se uma pergunta para o aluno que responde, e sua resposta se torna pergunta para o computador, que responde novamente. Essa é a interação reflexiva, onde o aluno se torna consciente do que improvisou por meio das repetições ou variações das respostas dadas pelo computador. Desta forma, há um feedback loop entre o que é improvisado pelo aluno e as respostas do computador que favorece o desenvolvimento da improvisação ao piano (piano digital).

A presença de feedback imediato na interação reflexiva "permite à criança ter uma percepção pertinente de sua intervenção em relação àquela do parceiro virtual" (ADDESSI et al., 2017, p.17). Por meio do feedback imediato da própria improvisação, ou seja, reprodução de improvisações, há uma comparação entre a improvisação que é desejada (intencional) e a improvisação alcançada (realizada), passando por um processo de aprendizado por erros, correções e adaptações, essenciais para o processo 
de improvisação (PRESSING, 1988 apud ADDESSI et al., 2017). Desta forma, feedback é crucial não só no aprimoramento de performances musicais (HAMOND, 2017; WELCH et al., 2005), mas também no desenvolvimento de improvisações musicais (ADDESSI et al., 2017).

\section{CONSIDERAÇÕES FINAIS}

Tecnologias digitais permitem o registro por meio de gravação de dados e consequente reprodução dos dados relacionados à performance de piano (HAMOND, 2017), do canto (WELCH et al., 2005) e a improvisações ou composições em instrumento de teclado (ADDESSI et al., 2017). Outros tipos de tecnologia que têm sido usados em aulas de piano de nível superior são o registro em vídeo (DANIEL, 2001), registro em áudio (ZHUKOV, 2010) e uso de programas de multimídia (BENSON, 1998). No entanto, os sistemas tecnológicos que são capazes de gravar e reproduzir (tocar o playback da gravação) seja em vídeo, áudio, DAW software e plataforma MIROR parecem ser ferramentas fundamentais para otimizar o ensino tradicional de piano. A reprodução dos dados gravados pela tecnologia pode oferecer aos professores e seus alunos oportunidades para avaliarem aspectos que podem ser melhorados e/ou mantidos em suas performances, improvisações e composições. O uso de tecnologia pode ser uma ferramenta útil para conscientizar os alunos nos seus processos de aprendizagem de suas performances no ensino de piano de nível superior (HAMOND, 2017) e de suas improvisações no ensino com crianças (ADDESSI et al., 2017).

A tecnologia digital pode proporcionar que os alunos vejam e ouçam suas performances ou improvisações numa perspectiva diferente daquela onde eles apenas tocam. O feedback visual combinado com o auditivo usado em tempo posteriori parece aumentar a consciência dos alunos de seus processos de aprendizagem e de suas próprias performances, ao lado dos tipos de feedback verbal e não verbal providos por seus professores (HAMOND, 2017). No caso da utilização do software MIROR-Impro, o feedback visual disponível através das visualizações em piano roll e do feedback auditivo ao ouvirem suas improvisações parece ter aumentado a percepção dos alunos sobre suas improvisações, tornando-os mais conscientes de seus processos de aprendizagem e dos elementos, variações melódicas e rítmicas e diversas texturas escolhidas durante o desenvolvimento das improvisações com o uso do software MIROR-Impro. Esses resultados se alinham com pesquisas anteriores, onde o feedback visual pode proporcionar um aumento do feedback intrapessoal do aluno e da consciência de seus processos de aprendizagem musical (HAMOND, 2017) e auxiliar na autorreflexão e autoavaliação de suas improvisações por meio de processo associativo auditivo-visual-motor (BISHOP; GOEBL, 2015; BROWN; PALMER, 2012; HALWANI et al., 2011).

Como sugerido em pesquisas anteriores (por exemplo, ADDESSI et al., 2017), o resultado dessa pesquisa contribui para a perspectiva do potencial pedagógico da interação reflexiva com o uso do software MIROR-Impro como ferramenta tanto para o desenvolvimento de competências musicais básicas para atuação na escola básica - como, por exemplo, execução, improvisação, composição e apreciação musical - 
quanto para o desenvolvimento de "competências pedagógicas relacionadas à interação criança-tecnologia, ao desenvolvimento e criatividade musical infantis e reflexão sobre o papel de professor em ambientes reflexivos" (ADDESSI et al., 2017, p.18). O uso do software MIROR-Impro parece beneficiar alunos de piano de formação clássica que possuem crenças de autoeficácia baixas em relação às suas habilidades de improvisação.

A tecnologia digital pode gerar tipos de feedback adicionais visuais e auditivos que não estão presentes no contexto da aula de instrumento tradicional. $O$ uso de tecnologias digitais tem sido uma prática comum em aulas de piano em grupo em cursos de Licenciatura em Música, por meio do uso de teclados e/ou pianos digitais (e pedal digital) e de fones de ouvido. Alunos de Bacharelado em Piano podem se beneficiar por meio do uso de piano digital e de outras tecnologias digitais, como, por exemplo, DAW software e interfaces MIDI e o software MIRO-Impro, adaptando e ampliando práticas pedagógicas tradicionais para o desenvolvimento de improvisações ao piano. Desta forma, mesmo que os alunos de bacharelado ou de licenciatura apresentem experiências prévias com a improvisação, tecnologias digitais como o software MIROR-Impro, quando utilizadas de forma sistemática, podem ser uma ferramenta para conscientizar aspectos melódicos, rítmicos e de texturas trabalhados na improvisação ao piano com mais objetividade através da gravação ou reprodução imediatas.

Pesquisas futuras podem estudar a interação reflexiva com uso do software MIROR-Impro em aula de piano em grupo com alunos de Licenciatura em Música com foco no desenvolvimento de improvisação, uma das habilidades funcionais a serem desenvolvidas para atuação como futuros professores de música na educação básica. Além disso, o uso do software MIROR-Impro pode ser investigado para o desenvolvimento da improvisação de alunos primeiramente como estudo individual, sem experiência prévia com improvisação e, subsequentemente, por meio da interação entre pares de alunos, replicando metodologias das pesquisas anteriores.

Investigações sobre o uso sistemático de tecnologias digitais em uma aula de instrumento, seja para aprimoramento de performances, seja para o desenvolvimento de improvisações, ainda são muito incipientes e precisam ser realizadas para uma maior compreensão do potencial pedagógico de tecnologias digitais em sala de aula e para quais propósitos de uso. No entanto, professores precisam estar abertos e se posicionar como aprendizes junto com seus alunos (WEBSTER, 2011), para que o ensino de música acompanhe os avanços tecnológicos, visando ao uso apropriado da tecnologia em sala de aula. Os resultados dessa pesquisa parecem ter efeito em mudanças ao nível curricular nos cursos de Bacharelado em Piano ou até mesmo de Licenciatura em Música, no conteúdo das aulas de piano, nos recursos utilizados para desenvolvimento de habilidades funcionais, como a improvisação, e também na capacitação de professores para a aplicação adequada de tecnologias digitais como ferramenta adicional ao contexto do ensino tradicional.

Agradecimentos. As autoras agradecem a todos os participantes desta pesquisa. 


\section{Referências}

ADDESSI, A. R. Developing a theoretical foundation for the reflexive interaction paradigm with implications for training music skill and creativity. Psychomusicology: music, mind, and brain, v. 24, n. 3, p. 214-230, 2014.

ADDESSI, A. R.; FERRARI, L.; CARUGATI, F. The Flow Grid: A technique for observing and measuring emotional state in children interacting with a flow machine. Journal of New Music Research, v. 44, n. 2, p. 129-144, 2015.

ADDESSI, A. R.; ANELLI, F.; BENGHI, D.; FRIBERG, A. Child-Computer interaction at the beginner stage of music learning: effects of reflexive interaction on children's musical improvisation. Frontiers in Psychology, v. 8, n. 65, p. 1-21, 2017.

ADDESSI, A. R.; BONFIGLIOLI, L. Interação reflexiva como paradigma transversal para a criatividade, educação musical e musicoterapia (Tradução: Rosane Cardoso de Araújo). Orfeu, v. 2, n. 2, p. 175-199, 2017.

BANDURA, A. Self-efficacy: the exercise of control. New York: W. H. Freeman and Company, 1997.

BANTON, L. J. The role of visual and auditory feedback during the sight-reading of music. Psychology of Music, v. 23, n. 1, p. 3-16, 1995.

BEINEKE, V. Composição em sala de aula: como ouvir as músicas que as crianças fazem? In: HENTSCHKE, L.; SOUZA, J. (orgs.). Avaliação em música: reflexões e práticas. São Paulo: Moderna, 2003. p. 91-105.

BEINEKE, V. Aprendizagem criativa na escola: um olhar para a perspectiva das crianças sobre suas práticas. Revista da Abem. Londrina, v. 19, n. 26, p. 92-104, 2011.

BRAA, K.; VIDGEN, R. Interpretation, intervention, and reduction in the organizational laboratory: a framework for in-context information system research. Accounting, Management and Information Technologies, v. 9, n. 1, p. 25-47, 1999.

BRAUN, V.; CLARKE, V. Using thematic analysis in psychology. Qualitative Research in Psychology, v. 3, n. 2, p. 77-101, 2008.

BURWELL, K. Instrumental teaching and learning in Higher Education. Thesis (PhD) University of Kent, Canterbury, 2010.

CERNEV, F. K. Aprendizagem musical colaborativa mediada pelas tecnologias digitais: 
uma perspectiva metodológica para o ensino de música. Revista da Abem, v. 26, n. 40, p. 23-40, 2018.

CHRISTENSEN, L. A survey of the importance of functional piano skills as reported by band, choral, orchestra, and general music teachers. Dissertation (Doctor of Philosophy) - University of Oklahoma, Norman, 2000.

COSTA, C. W. The Teaching of Secondary Piano Skills in Brazilian Universities. Dissertation (Doctoral) - University of Florida, Florida, 2003.

DUCATTI, R. H. A composição na aula de piano em grupo: uma experiência com alunas do curso de Licenciatura em Artes/Música. Dissertação (Mestrado) - Instituto de Artes, Universidade Estadual de Campinas, Campinas, 2005.

FINNEY, S. A.; PALMER, C. Auditory feedback and memory for music performance: sound evidence for an encoding effect. Memory \& Cognition, v. 31, n. 1, p. 51-64, 2003.

FRANÇA, C. C.; SWANWICK, K. Composição, apreciação e performance na educação musical: teoria, pesquisa e prática. Em Pauta, v. 13, n. 21, p. 5-41, 2002.

GLASER, S.; FONTERRADA, M. Músico-professor: uma questão complexa. Música Hodie, v. 7, n. 1, p. 27-49, 2007.

GUBA, E. G. Criteria for assessing the trustworthiness of naturalistic inquiries. Educational Communication and Technology, v. 29, n. 2, p. 75-91, 1981.

HAMOND, L. F. The pedagogical use of technology-mediated feedback in a higher education piano studio: an exploratory action case study. Thesis (PhD) - Institute of Education, University College London, London, 2017. (Unpublished)

HATTIE, J.; TIMPERLEY, H. The power of feedback. Review of Educational Research, v. 77, n. 1, p. 81-112, 2007.

HIMONIDES, E. The misunderstanding of music-technology-education: a meta perspective. In: MCPHERSON, G.; WELCH, G. (eds.). The Oxford Handbook of Music Education, v. 2, p. 433-456, Oxford: Oxford University Press, 2012.

KING, A. Collaborative learning in the music studio. Music Education Research, v. 10, $\mathrm{n}$. 3, p. 423-438, 2008.

MACHADO, S. G. A presença do piano em grupo em instituições de ensino superior no Brasil. Revista Orfeu, v. 1, n. 1, p. 132-155, jan./junho 2016. 
OLIVEIRA, M. A. W.; CERESER, C. M. I.; HENTSCHKE, L. Tecnologias de informação e comunicação na educação musical: um estudo de crenças de auto eficácia de professores de música no Brasil. Percepta: Revista de Cognição Musical, v. 3, n. 2, p. 81-99, 2016.

PACHET, F. Enhancing individual creativity with interactive musical reflexive systems. In: DELIĖGE, I.; WIGGINS, G. (eds.). Musical creativity: current research in theory and practice. New York: Psychology Press, 2006. p. 359-375.

PIKE, P. Dynamic group-piano teaching: transforming group theory into teaching pratice. New York, London: Routledge, 2017.

PSCHEIDT, J. F.; ARAÚJO, R. C.; ADDESSI, A. R. Interação reflexiva e criatividade musical empática. In: ARAÚJO, R. (org.) Educação musical: criatividade e motivação. Curitiba: Appris, 2019. p. 132-149.

ROCHA, J. L. S. Aprendizagem criativa de piano em grupo. São Paulo: Blucher, 2016.

SAVAGE, J. Reconstructing music education through ICT. Research in Education, v. 78, n. 1, p. 65-77, 2007.

SIEBENALER, D. J. Analysis of teacher-student interactions in the piano lessons of adults and children. Journal of Research in Music Education, v. 45, n. 1, p. 6-20, 1997.

SPEER, D. R. An analysis of sequential patterns of instruction in piano lessons. Journal of Research in Music Education, v. 42, n. 1, p. 14-26, 1994.

WEBSTER, P. R. Key research in music technology and music teaching and learning. Journal of Music, Technology and Education, v. 4, n. 2/3, p. 115-130, 2011.

WELCH. G. F. Os equívocos a respeito da música. Trad. Silvia Sobreira e Marcelo Almeida Sampaio. In: SOBREIRA, S (org.). Se você disser que eu desafino. Rio de Janeiro: UNIRIO, Instituto Villa-Lobos, 2017. p. 13-62.

WELCH, G. F.; HOWARD, F. M.; HIMONIDES, E.; BRERETON, J. Real-time feedback in the singing studio: an innovatory action-research project using new voice technology. Music Education Research, v. 7, n. 2, p. 225-249, 2005.

WÖLLNER, C.; WILLIAMON, A. An exploratory study of the role of performance feedback and musical imagery in piano playing. Research Studies in Music Education, v. 29, n. 1, p. 39-54, 2007. 